\title{
Taxes and Labor Supply: Portugal, Europe, and the United States (Conference Version)
}

\author{
André C. Silva* \\ Nova School of Business and Economics
}

November 2005

\begin{abstract}
I relate hours worked with taxes on consumption and labor. I propose a model and compare its predictions for Portugal, France, Spain, United Kingdom and United States. Hours per worker in Portugal decreased from 35.1 in 1986 to 32.6 in 2001 . With only the parameters and the taxes for Portugal, the model predicts the hours worked in 2001 with an error of only 12 minutes from the actual hours. Across countries, most predictions differ from the data by one hour or less. The model is able to explain the trend in hours with only the changes in taxes.
\end{abstract}

Keywords: labor supply, consumption tax, labor income tax.

\footnotetext{
* Nova School of Business and Economics, Universidade Nova de Lisboa. Campus de Campolide, 1099-032 Lisboa, Portugal. Email: acsilva@novasbe.pt. Tel: 351-21-380-1600. I thank Pedro Pita Barros, Susana Peralta and an anonymous referee for useful comments. All remaining errors are my own. This paper was prepared for the III Conference "Desenvolvimento Económico Português no Espaço Europeu," organized by the Banco de Portugal, which took place on February 2006. A technical version of this paper, with additional results on welfare and social security, has been published in the Portuguese Economic Journal, 7(2): 101-124, 2008, doi 10.1007/s10258-008-0029-1.
} 


\section{INTRODUCTION}

You may cook your dinner when arriving at home or you may heat prepared food. Heating prepared food requires less time. Regardless of your decision, when the price of prepared food increases it is more likely that you choose to cook your dinner. To do this, you will stop working earlier to arrive earlier at home or you will decrease your leisure time. Probably you will combine the two. Unless you decide to cut entirely from your leisure time, you will decrease your hours of work in the market.

Taxes influence our behavior because they change relative prices, that is, benefits and costs of different alternatives. The example above runs for a tax on consumption. We have a similar effect of a tax on labor income. We care for the goods that we can produce with our time. When the labor tax increases, we can buy less goods with the same amount of labor in the market. Therefore, there are more incentives to use our time in nonmarket activities as doing more domestic tasks, or increasing the leisure time.

Hours worked per worker in Portugal decreased from 35.1 hours per week to 32.6 hours per week from 1986 to 2001. The data are from the Organisation for Economic Co-operation and Development (OECD). Consumption and labor taxes increased during the same period. If we adjust a model to the average levels of hours and taxes for Portugal during 1986 to 1989 and let taxes vary but fix all other parameters, we can predict the number of hours worked and compare the predictions with their actual values. This exercise yields a prediction of 32.4 hours worked in 2001. According to these results, with only the change in taxes and abstracting from any other change in Portugal during these 15 years, we can predict the number of hours worked with an error of a little more than 10 minutes, or less than 1 percent from the true value! The same model predicts a decrease in the number of hours to 31.9 hours per week if there is a further increase of one percentage point of the taxes on consumption and 
labor.

The model does not make as precise predictions for all periods. It follows the general trend up or down of hours worked, but it misses, for example, a peak of hours worked in 1995. Nevertheless, the model is surprisingly precise to follow the general trend. Figure (1) shows the data and the predictions of the model in each year from 1986 to 2001. The results in this figure are for the parameters of the model calculated for Portugal. We will also calculate the parameters taking into account other countries and compare the new predictions with the data.

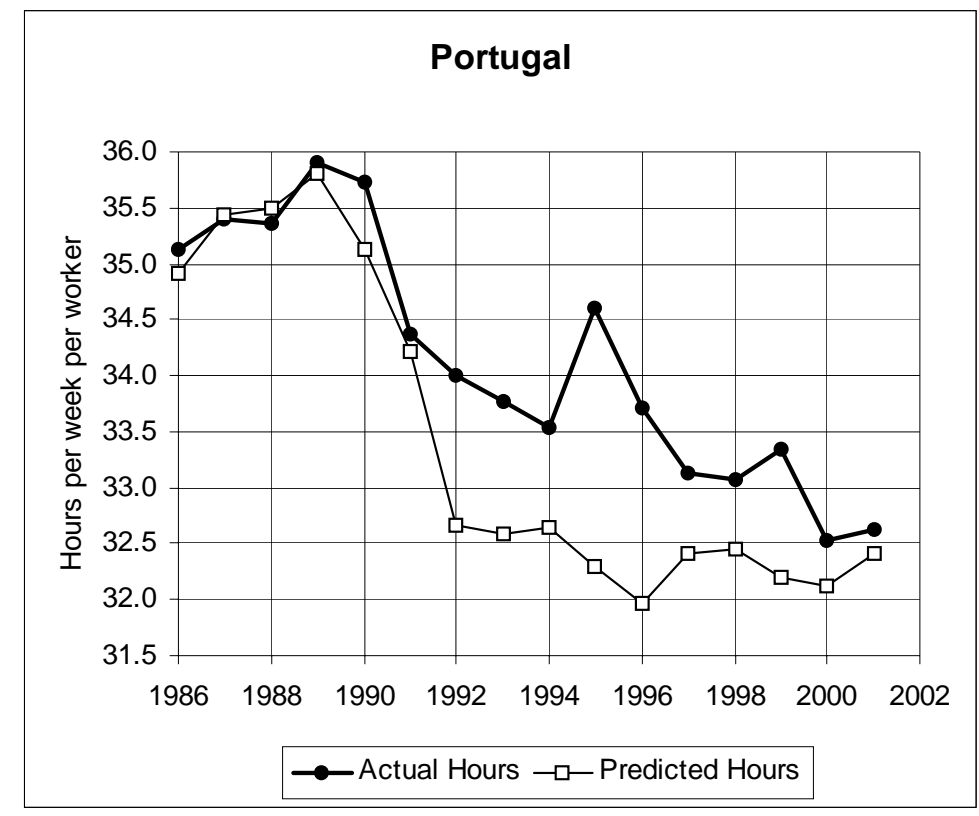

FIG. 1. Predicted hours obtained from the model developed in sections 2 and 3. Source of actual hours: OECD.

This paper is about the effects of consumption and labor taxes on labor supply. I will make the model and the definitions more precise in the following sections. I will focus on Portugal but I will also compare the predictions and the results with other countries. To do this we need to use data the most comparable as possible. For this reason, all data discussed here are from the OECD publications Revenue Statistics 
and National Accounts and the OECD labor market statistics. I expect that using the same source of data we can minimize the chance of committing errors as trying to explain something that is only an effect of different measurement standards. The appendix contains more details about the data sources.

Notice the implications of a decrease in hours worked in the market caused by an increase in taxes. One effect is the decrease in total production. With less products we also have less consumption and investment and less welfare. But it can be the case that the total number of hours stays constant but simply flows from market to nonmarket activities. Even in this case, we can still have welfare consequences.

When I say hours worked in the market I refer to hours used in the legal market for production. Hours not used in the market can be used for leisure or for nonmarket work. Leisure refers to activities that do not increase the quantity of goods and services available. Nonmarket work refers to domestic labor, as cooking your own dinner or teaching your children, or to work in the underground economy.

We use markets to specialize in some activities and increase our ability to produce more goods. I can produce an apple planting an apple tree in my backyard or buying it in a supermarket with my labor income. I prefer to use markets, that is, to use the supermarket, because I know that I will use my time better in this way.

Therefore, even if the total quantity of time devoted to work does not change when hours worked in the market decrease, we would probably be more efficient using the time in market activities. Moreover, the decrease in market work can also correspond to an increase in the underground economy. As taxes increase, the incentives for nonmarket work increase and so the economy works less efficiently.

I use the annual hours of work from the OECD and divide by 52 to obtain the weekly hours of work. I focus on the decision of hours worked and not worked in the market. If the workers in a country have less vacation for the same number of hours per working week then their annual hours of work in the market is higher. 
Consequently, their average number of hours per week is also higher.

The work is inspired by Prescott (2004) "Why do Americans work so much more than Europeans". He argues that the main factor able to explain the difference of income per capita in the United States and in the group of European countries Germany, France, Italy and the United Kingdom is the number of hours worked per person. The number of hours worked, in turn, can be almost fully explained by the higher taxes in the group of European countries.

Here I focus on the effects of taxation on the labor supply for different years. I investigate whether only taxes are able to explain the behavior of the number of hours worked in each year, and whether it can explain the difference in hours between countries. In addition to Portugal, I focus on the countries France, Spain, United Kingdom and United States.

I find that the increase in taxes during 1986 to 2001 is very good in predicting the behavior of labor supply in Portugal. Differences in taxes alone are not as precise in predicting differences in labor supply across Portugal and the other countries, but they are still able to explain a great part of the difference.

In section 2 below I discuss the effects of taxation on labor supply with an economic model. We then have to calculate the labor and consumption taxes for Portugal and other economies to compare the predictions of the model with the actual values of labor supply. There are several taxes in each economy with incidence on consumption and labor. We have to find a way to aggregate all these taxes in one number for consumption and another one for labor. This is done in section 3. In section 4, I use the calculated taxes to discuss the implications of the model, and discuss additional evidence on the effect of taxes on labor obtained in other settings. 


\section{TAXES AND THE DECISION OF CONSUMPTION AND LABOR}

What to expect from an increase in taxes regarding the decision of consumption and labor? We need to build a model with the following ingredients: a decision of how much to consume and work, taxes on consumption and labor, a government sector, and a production sector.

The elements of the following model are standard, it is the same model used by Prescott (2004). Its advantage is to model explicitly the decisions of consumers and firms, and the possibility to confront the predictions with data. Different versions of the model have been used in several applications. They can be found, for example, in the papers in Cooley (1995).

I treat all consumers in the economy as if they were represented as an average consumer or a representative consumer. When I mention the consumer, I am in fact making a reference to this representative consumer.

The only taxes that affect the decision of consumption and labor in each period are the consumption and the labor taxes. We can have other taxes in the economy as taxes on capital gains or taxes on investment but only consumption and labor taxes are important for our purposes. It is interesting to look first to the budget constraint of an average household to understand this behavior.

The budget constraint defines the resources available and their possible uses. Let us talk first about the resources. If the consumer works the number of hours $h_{t}$ at time $t$ for a wage $w_{t}$ then the labor income will be equal to $w_{t} h_{t}$. If there is a labor tax $\tau_{h}$ then the labor income after taxes, available for consumption, is equal to $\left(1-\tau_{h}\right) w_{t} h_{t}$. The time $t$ subscript stresses that the consumer must make a decision for each period. If the same consumer has a certain quantity of capital $k_{t}$ and the interest rate during the period is $r_{t}$ then the capital income will be equal to $r_{t} k_{t}$. If there is a tax on capital $\tau_{k}$ then this income will be subtracted by $\tau_{k}\left(r_{t}-\delta\right) k_{t}$, where $\delta$ stands for the 
depreciation of capital caused by its use. The government may also redistribute part of the taxes back to consumers in the form of transfers $T_{t}$, which are also part of the resources.

The possible uses of the resources are consumption, $c_{t}$, and investment, $x_{t}$. Consumption stands for consumption of goods and services. If the tax on consumption is $\tau_{c}$ then the price of a unit of consumption must be multiplied by $\left(1+\tau_{c}\right)$. Similarly, if the tax on investment is $\tau_{x}$ then the price of a unit of investment must be multiplied by $\left(1+\tau_{x}\right)$.

Therefore, a consumer in this economy faces the budget constraint

$$
\left(1+\tau_{c}\right) c_{t}+\left(1+\tau_{x}\right) x_{t}=\left(1-\tau_{h}\right) w_{t} h_{t}+r_{t} k_{t}-\tau_{k}\left(r_{t}-\delta\right) k_{t}+T_{t} .
$$

The left-hand side shows the possible uses for the resources: consumption and investment. The right-hand side shows the different resources: labor income, capital gains and transfers. The consumer has to decide the levels of $c_{t}, h_{t}$ and $x_{t}$ such that the constraint above is satisfied. The important variables for our purpose are $c_{t}$ and $h_{t}$.

Everything is in terms of the price of the consumption good. Therefore, if the consumer works one hour, it will be possible to consume $\left(1-\tau_{h}\right) w_{t}$ units of the consumption good.

The tax systems in the world are much more complicated than what we have in the budget constraint above. There are tax brackets, exemptions, subsidies for some investments and so on. But considering these complications will not change the basic point of the analysis. In section 3, I map the tax revenues and the tax bases to the relevant taxes in the model.

The quantity of capital and the quantity of investment are related. The quantity of capital tomorrow is equal to the quantity of capital today minus the depreciation 
from the use of capital plus any investment made today. In symbols, write

$$
k_{t+1}=(1-\delta) k_{t}+x_{t} .
$$

What is invested today will be available tomorrow in the form of capital and will generate an additional form of income tomorrow. Therefore, investment is only a way to connect consumption today with consumption tomorrow. As consumption and investment are connected, apart from the taxes $\tau_{c}$ and $\tau_{x}$, the price of a unit of investment is equal to the price of a unit of consumption. It is only a decision of consuming today or tomorrow.

The decision of working and consuming, on the other hand, affect the consumer in the same period. As capital will sooner or later be transformed in consumption, we can consider only the quantity of consumption and labor as the variables of interest in each period.

It is reasonable to admit that any additional amount of consumption makes the consumer happier. It is also reasonable to say that the quantity of time available for the consumer is fixed, and that any increase in the time available after working also makes the consumer happier. The time not working can be used to a nonmarket activity, as the production of goods to be consumed at home, or to be enjoyed as leisure. The number of hours $h_{t}$ refer to the quantity of work in the market. The model, therefore, considers the decision of consumption, labor and savings of an employed worker. It does not consider the decision of entering or not in the labor force as a job searcher.

If the quantity of hours worked in period $t$ increases one unit then the quantity of leisure decreases. If it were for only this effect the consumer would be worse off. But, from the budget constraint, the amount of resources will increase by $\left(1-\tau_{h}\right) w_{t}$ and this will allow the consumer to consume more. If this additional resource is 
used for consumption, the consumer will be able to consume $\frac{\left(1-\tau_{h}\right)}{\left(1+\tau_{c}\right)} w_{t}$ units of the consumption good.

The ratio $\frac{\left(1-\tau_{h}\right)}{\left(1+\tau_{c}\right)} w_{t}$ is key for this analysis. It relates how many units of the consumption good we are able to consume when we give up one unit of leisure. If taxes on labor or on consumption increase then the number of consumption units decrease. There are two important aspects to pay attention. The first is that taxes on capital income do not appear in this ratio. The second is that taxes on labor and on consumption have similar effects: a unit more of work will bring less goods if the labor tax is higher or if the consumption tax is higher. In fact, for small values of $\tau_{h}$ and $\tau_{c}$, the number $\left(1-\tau_{h}\right) /\left(1+\tau_{c}\right)$ can be approximated by $1-\tau_{h}-\tau_{c}$.

We need to be more explicit in the way the consumer weights the benefits of consumption and labor in order to make predictions as the ones contained in Figure $(1)$.

Suppose that consumption and labor in each period yield a level of welfare given by

$$
\log c_{t}+\alpha \log \left(100-h_{t}\right)
$$

The number 100 comes from the assumption that the consumer has 100 hours available in each week. The number of working hours have to be taken from these 100 hours. The parameter $\alpha$ is a positive constant. It will be used later to calibrate the model to the actual economies. The logarithmic function $\log X$ is increasing in $X$. Therefore, as consumption or leisure hours increase, the welfare in each period increases.

Our consumer evaluates consumption and leisure for all periods. But recent periods are valued more than later periods. That is, the period $t$ is discounted by the value $\beta^{t}$, where $\beta$ is greater than zero but less than one. The welfare of all periods is given by the sum of the terms $\beta^{t} \times\left(\log c_{t}+\alpha \log \left(100-h_{t}\right)\right)$ for $t=0,1,2$ etc. As the decision of consumption and labor depends on the values within a certain period, the 
parameter $\beta$ will not play an important role for our purposes

To close the model we need to define how products are produced and the role of government in this economy.

Products are produced by firms. They combine capital and labor to produce goods. Capital corresponds to the machines, tools and instruments used to manufacture the products. Capital and labor must be hired in the market, their prices are given respectively by $r_{t}$ and $w_{t}$. Let $y_{t}$ denote the value of production. Capital, labor and production are related by the production function

$$
y_{t}=A_{t} k_{t}^{\theta} h_{t}^{1-\theta} .
$$

The constant $\theta$ is positive and between zero and one. So, when capital or labor increase, production increases. $\theta$ is equal to the fraction of capital income in the total income. Correspondingly, $1-\theta$ is equal to the fraction of labor income in the total income. This parameter does not vary much from country to country and during different time periods. The parameter $A_{t}$ is called total factor productivity. According to this model, if two countries use the same quantity of labor and capital but produce different quantities of the consumption good it is because $A_{t}$ is different between them. But $A_{t}$ will not affect the quantity of hours worked and will not be important for our purposes.

Profits are given by the difference between revenue and costs. Profits are therefore given by

$$
A_{t} k_{t}^{\theta} h_{t}^{1-\theta}-w_{t} h_{t}-r_{t} k_{t} .
$$

A useful result is that, in order to maximize profits, each firm will set the quantity of capital and labor so that wages and the production function are related by

$$
w_{t}=(1-\theta) \frac{y_{t}}{h_{t}} .
$$


There is also another condition for the interest rate. As interest rates do not enter in the decision of consumption and labor within periods, we will not use this additional condition here.

Total production is used for consumption and investment. The government also uses part of the production to provide goods for the citizens. Let $g_{t}$ denote the quantity of goods consumed by the government and left to the consumer. Some examples of this kind of good are public schooling, police service and the maintenance of public parks. Total consumption in this economy is given by $c_{t}+g_{t}$. As consumption and investment must come from production, we have

$$
c_{t}+x_{t}+g_{t}=y_{t}
$$

The government collects taxes to pay for government consumption. Any difference between the government's revenue and the government consumption is given back to consumers in the form of transfers $T_{t}$. Therefore, the government budget constraint is given by $g_{t}+T_{t}=$ revenues from taxes.

\section{Solving the model}

The variable that we do not know and need to find is the number of hours worked in each period, $h_{t}$. Solving the model means writing $h_{t}$ as a function of the tax rates and of the parameters $\theta$ and $\alpha$. We do not know $c_{t}, x_{t}$ and $k_{t}$ either and a full solution also involves obtaining these variables. Here we are concerned with the behavior of hours worked and so we will concentrate on $h_{t}$.

The value of $h_{t}$ depends on how consumers value consumption and leisure, and on how firms value the use of labor and capital.

From the standpoint of consumers, when they increase one unit of labor they have a

decrease in welfare of $\frac{\alpha}{100-h_{t}}$ as implied by how they value consumption and leisure 
in (3). On the other hand, this unit of labor allows them to buy $\frac{1-\tau_{h}}{1+\tau_{c}} w_{t}$ units of the consumption good and yields an increase in welfare of $\frac{1}{c_{t}} \frac{1-\tau_{h}}{1+\tau_{c}} w_{t}$. Consumers will increase the quantity of labor until the benefits are greater than the loss in welfare. Therefore, they will choose consumption and labor so that

$$
\frac{\alpha}{100-h_{t}}=\frac{1}{c_{t}} \frac{1-\tau_{h}}{1+\tau_{c}} w_{t}
$$

Firms choose capital and labor so that $w_{t}=(1-\theta) y_{t} / h_{t}$. With this, we have

$$
\frac{\alpha}{100-h_{t}}=\frac{1}{c_{t}} \frac{1-\tau_{h}}{1+\tau_{c}}(1-\theta) \frac{y_{t}}{h_{t}}
$$

or

$$
h_{t}=100 \times \frac{1-\theta}{1-\theta+\alpha \frac{c_{t}}{y_{t}} \frac{1}{1-\tau}},
$$

where $1-\tau=\frac{1-\tau_{h}}{1+\tau_{c}}$.

Equation (9) is the key to understand how taxes influence labor supply. If taxes on labor or on consumption increase, then $\tau$ increases, the denominator increases and so the number of hours worked, $h_{t}$, decreases. The ratio of consumption to production, $c_{t} / y_{t}$, depends on the expectations about the future. For example, if taxes are higher in the future relative to today then it is better to work more now, save the additional proceeds, and use the savings in the future. The additional savings will decrease the ratio of consumption to production.

Figure (2) shows data on hours per worker for Portugal and for the United States from 1986 to 2001 and the values of $\tau$ for the two countries in the same period. We see that hours per worker decreased more in Portugal and that taxes increased more in Portugal. This observation agrees with the model. To be more precise, we have to substitute the values of $\tau$ and $c_{t} / y_{t}$ in the formula above and compare the predictions 
of the model and the actual values of hours per worker. This is the subject of the next sections. First, we have to calculate the tax rates to be used in equation (9).

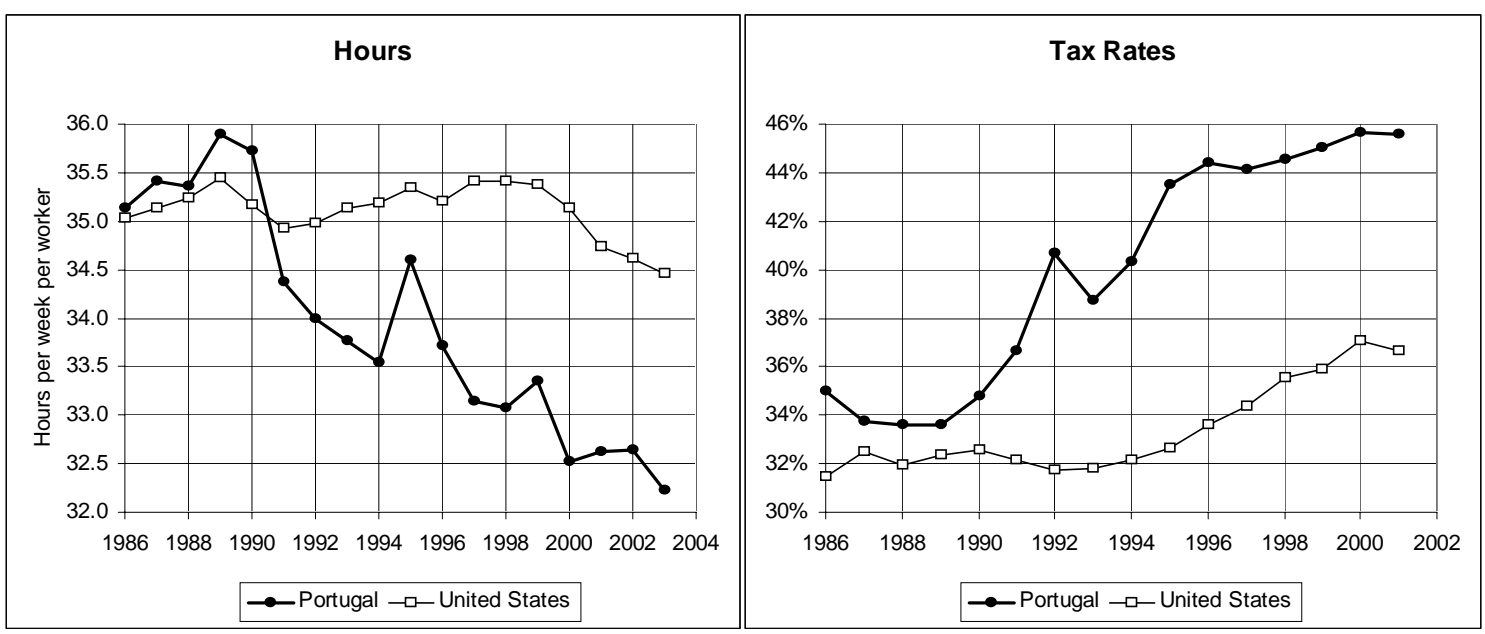

FIG. 2. Source for Hours: OECD. Tax rates: calculations by the author following section 3 .

\section{TAXES ON LABOR INCOME AND CONSUMPTION}

We have to calculate the value of taxes over the years. Consider the tax on consumption for example. We have different taxes with incidence over the various goods and services traded in the economy. Usually taxes are small for basic food and high for luxury goods. In the model, the unique good represents all kinds of goods and services. Therefore, the tax on consumption $\tau_{c}$ must represent the tax on all goods and services.

The same idea applies to the labor tax. The income tax systems are progressive over income and allow for exemptions and deductions. We also have social security taxes paid by workers. Moreover, we have to consider the difference between marginal tax rates and average tax rates. Consumers decide over consumption or labor according to the tax rate paid over one additional unit of labor. This is the marginal tax rate 
on labor. Hence, consumers make decisions according to the marginal tax rate, and not according to the average tax rate.

The calculations follow the same principle: dividing the revenues from the tax by the tax base. We have data of tax revenue detailed by the origin for all OECD countries from the OECD database. We also have data for National Accounts aggregates as consumption and GDP from the same database. Using this data and the procedure described in detail in the next paragraphs, I obtained the taxes in figures (3) and (4).

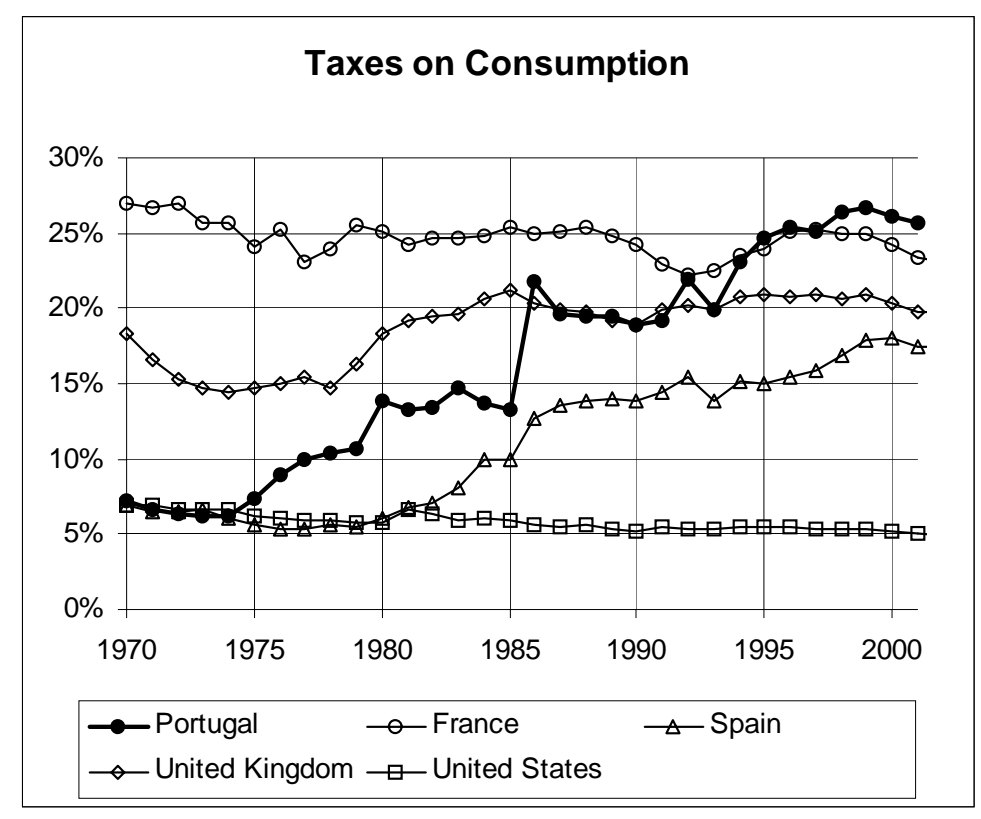

FIG. 3. Source: author's calculations based on OECD data.

The idea of using National Accounts aggregates to calculate effective tax rates has its origins in Lucas (1990) and was extended by Mendoza, Razin and Tesar (1994). Prescott (2002) and Prescott (2004) also used this method and I am following closer his calculations. There are some differences in my calculations in order to yield longer series and being the most comparable as possible. Calculating directly using Mendoza-Razin-Tesar's method yields slightly different values. But the differences do 


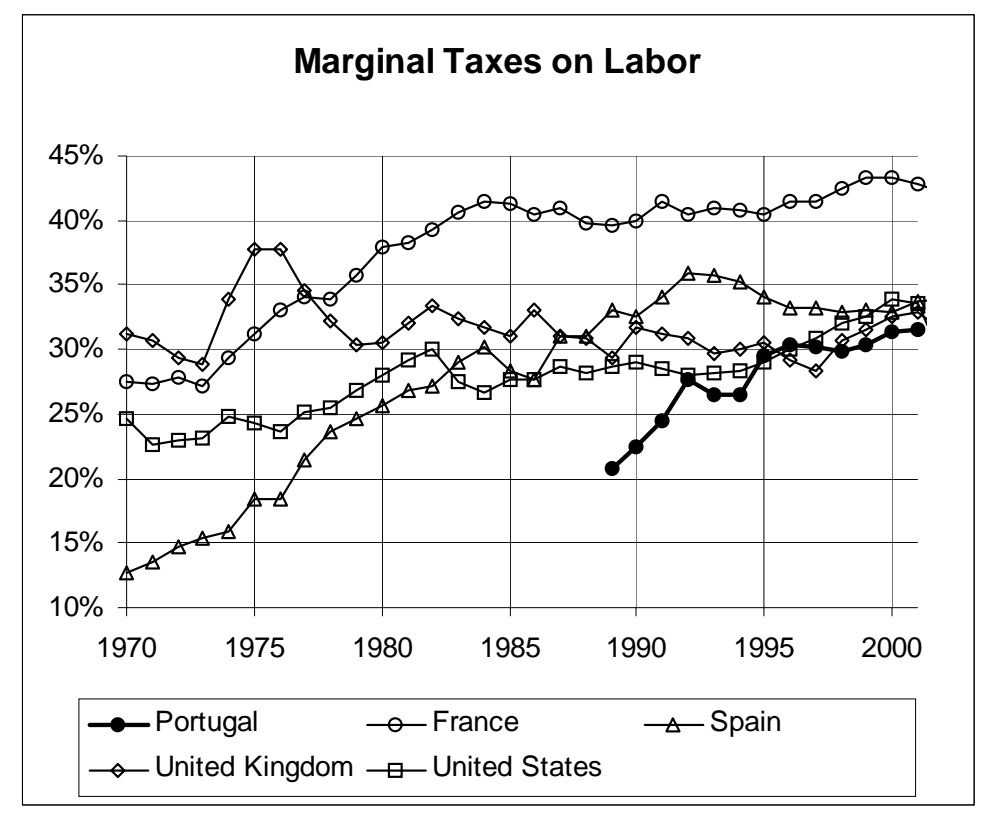

FIG. 4. Source: author's calculations based on OECD data.

not modify the conclusions as I calculate the taxes for each country using the same procedure.

The sources of data are from the OECD publications National Accounts, Detailed Tables: vol II and Revenue Statistics of OECD Member Countries. The codes of the items used in the calculations are in the appendix.

For the tax on consumption $\tau_{c}$ I divide the revenues from indirect taxation by household final consumption expenditure minus indirect taxation. The revenues considered for the consumption tax come from general taxes from goods and services and from excise taxes. Final consumption expenditures takes into account indirect taxation in the National Accounts. Therefore, we have to subtract these taxes to find the relevant tax base.

As Mendoza-Razin-Tesar note, part of the indirect taxation comes from taxes paid by the government. This requires summing the tax base by the difference between 
government consumption and wages paid to government employees. As the denominator is bigger with the government sector, the tax on consumption calculated in this way is smaller. However, I compared the calculations with the two methods and the two series are very close, moving almost in parallel. For Portugal, the OECD database would allow us to calculate consumption taxes only for the period 1995-2001. The difference between the calculations with or without the government sector are about five percentage points for this period. The advantage of using the simpler formulation is that it is possible to construct a longer series.

For the tax on labor income $\tau_{h}$ we have to calculate the social security tax and a measure for the marginal income tax not including the social security tax.

The social security tax is obtained by dividing the social security contributions by the labor income. From equation (6) of the model in section 2, the share of labor income over total production is equal to $1-\theta$. Therefore, I use $(1-\theta)$ times GDP less indirect taxes as an estimate of the labor income. We have to subtract indirect taxes from GDP because the National Accounts figures include the payment of taxes. I set $1-\theta=0.7$. This share is approximately constant over countries and time and the number used is conventional in models of this type. Gollin (2002) obtains further evidence for this number and for the stability of the labor share across countries. The difficulty for the calculation of the labor shares results from the estimation of the labor income of the self-employed. Gollin (2002) finds that the labor shares are approximately constant, in the range of 0.65 and 0.80 , once the labor income of the self-employed is treated carefully. The conclusions of the present analysis do not change if we consider other values for this parameter in this range.

The average income tax is calculated by dividing the revenue from taxes of individuals by GDP less indirect taxes less the depreciation of capital. Consumers care for the tax payments of an additional unit of labor. This marginal tax rate is higher than the average tax rate because tax rates are usually higher when incomes are higher. To 
obtain the marginal tax rate, I follow Prescott $(2002,2004)$ and multiply the average tax rate by the factor 1.6. The labor income tax is then obtained as the sum of the social security tax and the marginal labor income tax.

\section{DATA AND PREDICTIONS}

We now turn to the predictions of the model. I repeat the key equation for the predictions of the model for convenience

$$
h_{t}=100 \times \frac{1-\theta}{1-\theta+\alpha \frac{c_{t}}{y_{t}} \frac{1}{1-\tau}},
$$

where $1-\tau=\frac{1-\tau_{h}}{1+\tau_{c}}$. The taxes $\tau_{h}$ and $\tau_{c}$ are the labor income and consumption taxes.

The objective of this section is to use the same model for different countries and verify if the difference in the tax rates is able to explain most of the difference in hours worked. In addition to Portugal the countries chosen for this study were France, Spain, United Kingdom and United States. I first focus on four periods: 1970-1974, 1983-1986, 1993-1996 and 2000-2002. The first period is the first that we have data available for France, United Kingdom, and United States. The first observation available for Portugal is in $1986^{1}$, therefore I included the period 1983-1986. The period 2000-2002 is the last period that we have data available. Prescott (2004) focuses on the periods 1970-1974 and 1993-1996.

Several other important features may affect the number of hours worked and labor market statistics. For example, Bover, Garcia-Perea and Portugal (2000) and Blanchard and Portugal (2001) analyze how institutional structures such as unemployment

\footnotetext{
${ }^{1}$ Labor income taxes are available since 1989 for Portugal. I maintained the labor income tax rate during 1986-1988 equal to its value in 1989 to calculate $\tau$ from 1986 to 1988.
} 
benefits, unions and other factors can affect unemployment and unemployment duration. Here I focus on taxes and the differences in hours worked.

I used two estimates for $c_{t}$ in equation (9). In the first case I considered only private consumption net of indirect taxes. In the second I also considered government consumption. So, $c_{t}=C_{t}$ - Indirect Taxes in the first case and $c_{t}=C_{t}+G_{t}-$ Indirect Taxes in the second case. $C_{t}$ and $G_{t}$ are the figures of private and government consumption in the National Accounts data. The value of $y_{t}$ is the same in the two cases: $y_{t}=G D P-$ Indirect Taxes.

The justification for considering government consumption as part of $c_{t}$ is that this value may substitute part of private consumption. However, I do not have a clear estimate of the degree of substitution between private and government consumption. Therefore, I calculated the predictions for the two extreme cases, with zero or oneto-one substitution, and compared with the actual values.

The parameter $\alpha$ sets the weights between consumption and leisure. It should have the same value for all countries to assess how much of the difference in hours is explained by the difference in taxes only. This parameter is obtained so that the difference between the actual and the predicted values of hours worked is minimized for the period 1970-1975 for France, United Kingdom and United States. It yields $\alpha=1.39$ and $\alpha=1.02$ when we consider respectively private consumption only and private and government consumption. The predictions of figure (1) were obtained for a value of $\alpha$ set to minimize the difference during the period 1986-1989 for Portugal, with only private consumption. This yields $\alpha=1.47$ and is used to assess how much of the change in hours during the period 1986-2001 may be accounted for changes in the tax rates for Portugal.

Therefore we estimate the parameter $\alpha$ in two ways. In the first way we focus on Portugal and obtain the first predictions in figure (1) as a starting point. In the second way we do not use the data for Portugal and use other countries and another period. 
In this second way the parameter $\alpha$ is set independently from the data for Portugal. Any difference in the predictions of hours worked across countries and through time is because of the difference in taxes and the difference in the ratio of consumption to GDP. I now focus on this second estimation of $\alpha$.

Table 1 compares the actual hours and the predicted hours using the model for the countries studied. Each period has the average of the actual and the predicted values. Each column for a prediction fixes the same value of $\alpha$ for all countries. Therefore, I fix tastes on consumption and leisure and all kinds of institutional arrangements across countries. I allow only taxes to vary and the corresponding equilibrium value $c_{t} / y_{t}$.

Table 1. Actual and Predicted Hours

\begin{tabular}{|c|c|c|c|c|c|c|c|c|c|}
\hline & \multicolumn{3}{|c|}{ Portugal } & \multicolumn{3}{|c|}{ France } & \multicolumn{3}{|c|}{ Spain } \\
\hline & Actual & Pred 1 & Pred 2 & Actual & Pred 1 & Pred 2 & Actual & Pred 1 & Pred 2 \\
\hline 1970-74 & - & - & - & 35.9 & 37.2 & 36.4 & - & - & - \\
\hline $1983-86^{*}$ & 35.1 & 36.2 & 37.7 & 31.6 & 31.9 & 29.6 & 36.0 & 35.3 & 36.8 \\
\hline 1993-96 & 33.9 & 33.6 & 33.5 & 30.2 & 32.6 & 29.9 & 34.9 & 33.9 & 34.0 \\
\hline \multirow[t]{3}{*}{$2000-02^{* *}$} & 32.6 & 33.5 & 32.4 & 28.3 & 32.4 & 29.8 & 34.9 & 34.6 & 34.7 \\
\hline & & \multicolumn{3}{|c|}{ United Kingdom } & \multicolumn{5}{|c|}{ United States } \\
\hline & & Actual & Pred 1 & Pred 2 & & Actual & Pred 1 & Pred 2 & \\
\hline 1970-74 & & 36.6 & 34.8 & 34.8 & & 36.3 & 37.0 & 38.1 & \\
\hline 1983-86 & & 33.5 & 34.4 & 33.2 & & 35.1 & 35.2 & 36.5 & \\
\hline 1993-96 & & 33.3 & 33.7 & 33.4 & & 35.2 & 33.8 & 35.9 & \\
\hline 2000-02 & & 32.8 & 32.3 & 32.3 & & 34.8 & 32.1 & 34.5 & \\
\hline
\end{tabular}

Hours per week per worker. Pred 1: predictions with private consumption. Pred 2: predictions with private and government consumption. * 1986 only for Portugal. ** 2000-01 only for Portugal.

Source of actual hours: OECD.

Although the model abstracts from several potentially important features of the labor market, it is able to generate very reasonable estimates based only on the tax 
rates. Most of the numbers are around one hour of error from the actual value of hours worked. Only five predictions misses the actual numbers for more than two hours.

According to table 1, the predictions for hours worked for Portugal are above the actual values for 1986 and are much closer for 1993-96 and 2000-01. For Spain, in only one period the model predicts the hours with more than one hour of error. For the United Kingdom it misses the period 1970-74 but it is good in predicting the other periods. For France, the model predicts more hours of work than the actual values specially for the period 2000-2002. It can be an effect of the new legislation on the reduction of the working week in France, and it can have a greater role than the change in taxes for this period.

Therefore, the model is good in predicting the general pattern of hours worked even though it misses some observations. As everything is fixed across countries and only taxes are allowed to vary, this shows that taxes have an important effect in the number of hours worked. The good fit is more surprising for Portugal and Spain as I have not used these countries to estimate the value of $\alpha$, and we could believe a priori that they are much different from the other countries apart from the difference in taxes. See figures (5)-(7) for the comparison of actual and predicted hours year by year.

I am using hours per worker as a benchmark to compare the predictions of the model. We can also think about using hours per capita, or hours per person in the active population. In the model, the worker decides how much to work in one job, and therefore hours per worker seem appropriate to use as the benchmark. It states how many hours someone will work, given the fact that the decision of entering the labor market has already been made. If the consumer is an average worker, taking into account those that are in the labor force and those there are not, hours per capita may also seem appropriate. 


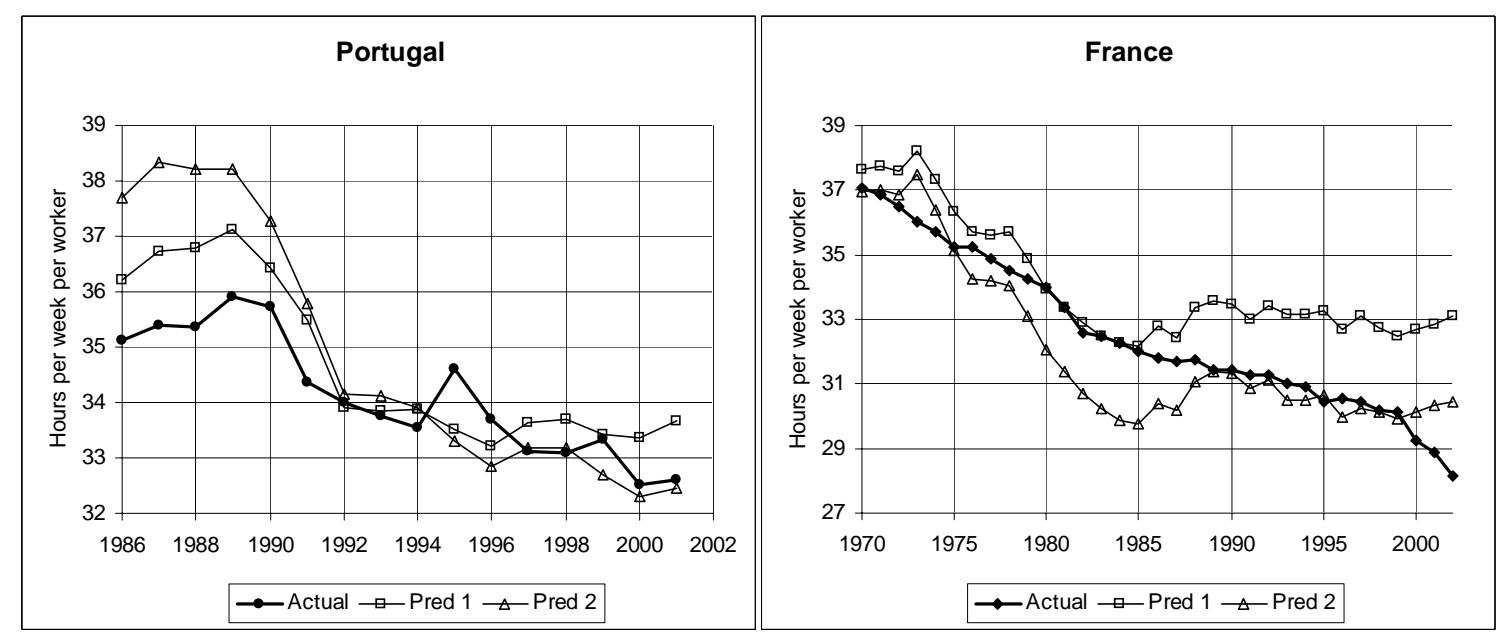

FIG. 5. Source of actual hours: OECD. Pred 1: predictions using only private consumption net of indirect taxes. Pred 2: predictions with private and government consumption net of indirect taxes.

Hours per working age person in Portugal are on average 2.4 hours lower than in the United States during 1986 to 2001. During the same period, however, hours per person were more or less constant as the number of people in the labor force increased. Prescott (2004) uses hours per working age person (by convention, people aged 15 to 64 ) and he also finds an important effect of taxes on the supply of labor. He notes, however, that hours per capita increased in the United States during 19701990 although taxes increased or remained approximately constant. He then notices that households switching from one wage earner to two wage earners may explain this behavior. In my analysis, I abstract from this possibility.

Davis and Henrekson (2004) show further evidence on the impact of consumption and labor income taxes on labor supply. They use an empirical analysis to study the relation between taxes and labor supply. They find that a 12.8 percentage points increase in the tax rate implies 122 market work hours per year per adult, a decrease of 4.9 percentage points in the employment-population ratio, and an increase in the 


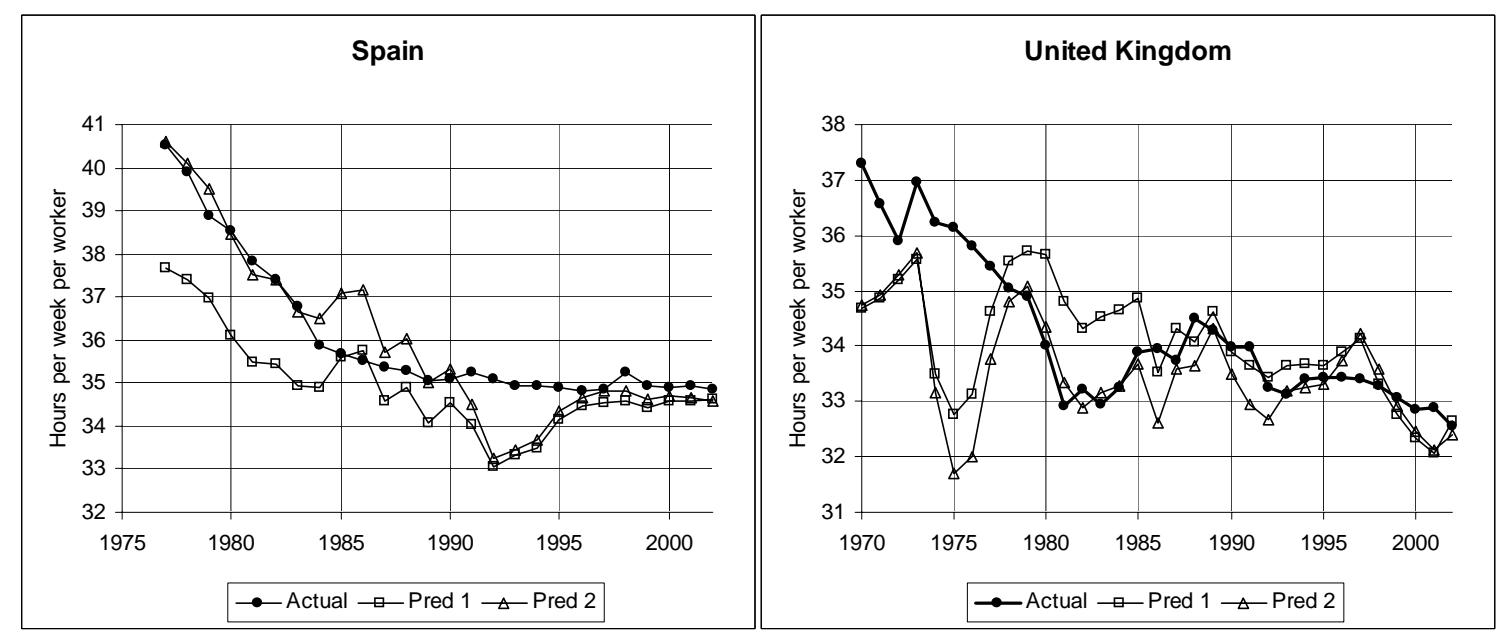

FIG. 6. Source of actual hours: OECD. Pred 1: predictions using only private consumption net of indirect taxes. Pred 2: predictions with private and government consumption net of indirect taxes.

shadow economy equal to 3.8 percent of GDP. It also decreases employment in retail trade and repairs, and in eating, drinking and lodging. The increase in taxes affect more heavily these industries with less-skilled labor as it is easier to substitute market work for domestic work in these sectors.

There are also other explanations for the difference of labor supply in Europe and in the United States. Alesina, Glaeser and Sacerdote (2005) state that policies of the unions and labor market regulations are able to account for most of the difference in labor supply.

\section{CONCLUSIONS}

Tax rates affect the decision of labor supply by changing the relative benefits and costs of work and consumption. The effect is large. For Portugal, France, Spain, United Kingdom and United States, taxes are able to predict the pattern of the labor supply over the years. 


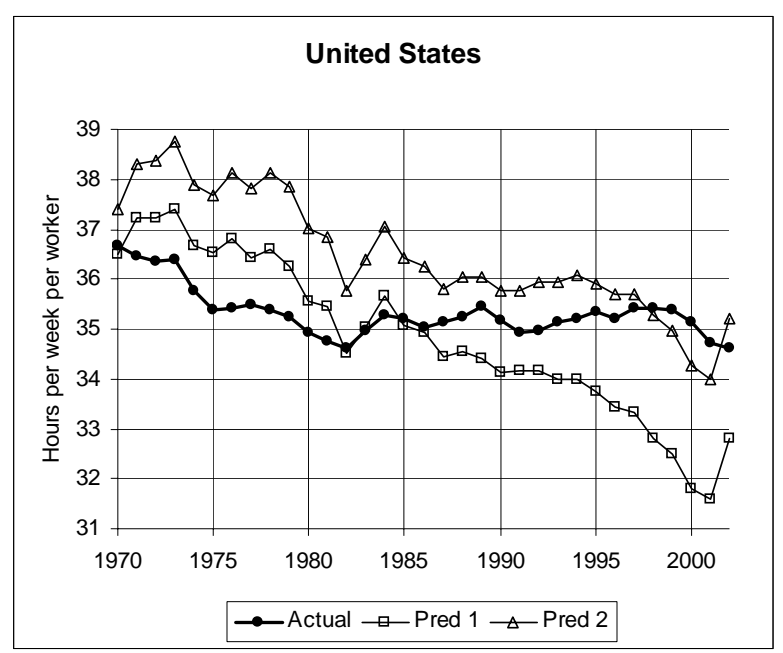

FIG. 7. Source of actual hours: OECD. Pred 1: predictions using only private consumption net of indirect taxes. Pred 2: predictions with private and government consumption net of indirect taxes.

I first estimate the tax rates for the countries considered during 1970 to 2001. For all countries, taxes increased during the period and the number of hours worked decreased. I then compare the predictions of the model on hours worked per worker with the actual values for each country. Most of the predictions are different from the actual values by one hour or less. The model is able to follow the general pattern of labor supply.

Hours refer to hours working in the market. When the number of hours worked decreases, the number of nonmarket hours increases. These hours may be leisure hours or hours used in the production of nonmarket goods, as domestic production. Production is a function of hours worked. With a decrease in the number of hours worked, the number of consumption goods decreases. Therefore, when consumers decide to work less hours, they consume less products in the market and increase their consumption of leisure or nonmarket goods.

If we are more efficient trading goods in the market, a decrease in market hours 
makes consumers less efficient. A result in Economics is that decisions are efficient when the costs and benefits are equalized by consumers and firms. With taxes, consumers receive a wage but can buy goods only with the after-tax wage. Therefore, firms and consumers do not equalize the costs and benefits of the labor decision.

GDP per capita in Portugal increased from US\$10,700 to US\$17,100 during the period from 1986 to 2003 . These are figures in dollars of 2000 corrected for purchasing power. Relative to the United States, GDP per capita in Portugal increased from 41 to 48 percent during this period. In order to continue growing at high growth rates we have to look for ways to make the economy more efficient. Paying attention to the incentives that make consumers decide on their use of time is one of them.

\section{APPENDIX - DATA SOURCES AND FORMULAS FOR THE TAX RATES}

The sources of data for National Accounts and Revenue Statistics are from the OECD (Organisation for Economic Co-operation and Development) publications $\mathrm{Na}$ tional Accounts, Detailed Tables: vol II and Revenue Statistics of OECD Member Countries. I use the OECD online dataset SourceOECD. For the labor force, I use the data available online from the OECD following the path Statistics/Data by Topic/Labour/Labour Force Statistics - Data, "Average actual annual hours worked

per person in employment". I divide the annual hours by 52 to write the values in weekly hours. For the figures of GDP per capita, I use the "Comparative tables based on exchange rates and PPPs".

The formulas for the tax rates on consumption and labor are

$$
\begin{gathered}
\tau_{c}=\frac{I T}{C-I T}, \\
\tau_{h}=\tau_{S S}+1.6 \tau_{h}^{a v g} .
\end{gathered}
$$


$\tau_{c}$ and $\tau_{h}$ denote respectively the tax rate on consumption and the marginal tax rate on labor income. $\tau_{S S}$ and $\tau_{h}$ denote respectively the social security tax and the average tax rate on labor income. $C$ denotes consumption expenditures and IT denotes indirect taxes on consumption. In the National Accounts, the final price of the products are used to calculate aggregate consumption expenditures $C$. Therefore $C$ takes into account the indirect taxation. Therefore, we have to subtract indirect taxation from consumption expenditures to find the relevant tax base.

The social security tax and the average labor income tax are obtained by

$$
\begin{gathered}
\tau_{S S}=\frac{\text { Social Security Contributions }}{(1-\theta)(G D P-I T)}, \\
\tau_{h}^{a v g}=\frac{\text { Direct Taxes of Individuals }}{G D P-I T-\text { Depreciation }} .
\end{gathered}
$$

The parameter $\theta$ is the fraction of capital income in the total income. Hence, $1-\theta$ is equal to the fraction of labor income in the total income. In the Revenue Statistics, social security contributions are given by the item 2000, IT is given by the sum of the items 5110 and 5121 and Direct taxes of individuals is given by the item 1100 . We have to subtract indirect taxes from GDP because the value of the GDP in the National Accounts includes indirect taxes. See section 3 for the explanation of the formulas.

\section{REFERENCES}

Alesina, Alberto, Edward Glaeser and Bruno Sacerdote (2005). "Work and Leisure in the U.S. and Europe: Why So Different?" NBER Working Paper 11278.

Blanchard, Olivier and Pedro Portugal (2001). "What Hides Behind an Unemployment Rate: Comparing Portuguese and U.S. Labor Markets." American Economic Review, 91(1): 187-207. 
Bover, Olympia, Pilar Garcia-Perea and Pedro Portugal (2000). "Labour Market Outliers: Lessons from Portugal and Spain." Economic Policy, 31: 379428.

Cooley, Thomas F., ed. (1995). Frontiers of Business Cycle Research. Princeton: Princeton University Press.

Davis, Steven J. and Magnus Henrekson (2004). "Tax Effects on Work Activity, Industry Mix and Shadow Economy Size: Evidence from Rich-Country Comparisons." NBER Working Paper 10509.

Gollin, Douglas (2002). "Getting Income Shares Right." Journal of Political Economy, 110(21): 458-474.

Lucas, Robert E., Jr. (1990). "Supply-Side Economics: an Analytical Review." Oxford Economic Papers, 42: 293-316.

Mendoza, Enrique G., Assaf Razin, and Linda L. Tesar (1994). "Effective Tax Rates in Macroeconomics: Cross-Country Estimates of Tax Rates on Factor Incomes and Consumption." Journal of Monetary Economics, 34(3): 297-323.

Prescott, Edward C. (2002). "Prosperity and Depression." American Economic Review, 92(2): 1-15.

Prescott, Edward C. (2004). "Why Do Americans Work So Much More Than Europeans?" NBER Working Paper 10316. 